\section{Yield, maturation cycle, and estimates of genetic parameters of Robusta coffee genotypes under irrigation in the Cerrado}

\section{Mateus Rollemberg Santin ${ }^{1 *}$, Mateus Costa Coelho ${ }^{1}$, Ricardo Menezes Sayd ${ }^{1}$, José Ricardo Peixoto ${ }^{1}$ and Renato Fernando Amabile $^{2}$}

\begin{abstract}
Eighty-five Coffea canephora genotypes were evaluated for three crop seasons under irrigation in the Cerrado of the Distrito Federal, Brazil, to characterize the population regarding phenotype, yield and maturation cycle. The experiment was conducted through the Basic Model of Repeatability without Design methodology. Regarding the cycles, genotypes were divided into four groups with the following periods, in days, from resumption of irrigation to the cherry stage: very early (243-255), early (256-267), medium (268-280), and semilate (281-293). For yield, the repeatability obtained was approximately $33 \%$, a medium value that represents the proportion of the permanent phenotypic variance in relation to the total phenotypic variance. The average repeatability obtained surpassed 59\%, and accuracy, with three crop seasons, reached $77 \%$. The selection gains obtained may be higher than 38\%. There are promising genotypes for cultivation in the region under study. The mean repeatability and the accuracy obtained favor selection based on phenotypes.
\end{abstract}

Keywords: Coffea canephora Pierre ex Froehner, repeatability, phenotypic variance, crop breeding.

\section{INTRODUCTION}

The Coffea canephora species, though high yielding, is less planted than Coffea arabica in Brazil, and is practically restricted to the states of Espírito Santo and Rondônia. C. canephora is better adapted to the soil and climatic conditions of tropical regions of low altitudes and high air temperatures. Thus, it is not commonly grown in the Cerrado (tropical savanna) of Central Brazil, where it should be established through selection of genotypes adapted to a climate with especially low nighttime temperatures in the winter and to the cultivation system of the region, specifically to mechanized harvesting.

When cultivated at high altitudes, $C$. arabica usually performs better than C. canephora, and the opposite is perceived in warm lands at lower altitudes (Rodrigues et al. 2016). Partelli et al. (2011) quote several authors reporting that low air temperatures limit the geographic distribution of coffee, especially when monthly averages are below $15-16{ }^{\circ} \mathrm{C}$; photosynthesis is already affected below $18{ }^{\circ} \mathrm{C}$, and severe cold (chilling and daytime temperatures remaining around $15^{\circ} \mathrm{C}$ and nighttime temperatures below $10^{\circ} \mathrm{C}$ ) has serious consequences on yield. However, the authors also clarify that the plants have a certain capacity for acclimatization to cold.
Crop Breeding and Applied Biotechnology 19(4), 387-394, 2019 Brazilian Society of Plant Breeding. Printed in Brazil http://dx.doi.org/10.1590/198470332019v19n4a55
*Corresponding author: E-mail: mateusantin@gmail.com (iD) ORCID: 000-0001-5861-8004

Received: 27 October 2017 Accepted: 25 July 2019

${ }^{1}$ Universidade de Brasília, Campus Universitário Darcy Ribeiro, 70.910-900, Brasília, DF, Brazil

2 Embrapa Cerrados, Rodovia BR 020, km18, 73.310-970, Brasília, DF, Brazil 
The Cerrado has been very conducive to coffee growing, especially when using technologies such as irrigation and mechanized farming practices (Fernandes et al. 2012), especially harvest. The same authors state that a significant limitation for $C$. canephora in the Cerrado is associated with low temperatures in high altitude areas. However, due to considerable genetic diversity within this species (Fonseca et al. 2006), different mechanisms of tolerance to low temperatures are used (Partelli et al. 2011). From this, it can be inferred that selection of materials adapted to cultivation in the central region of Brazil is possible.

Because coffee is a biennial crop, coffee plants have vegetative growth and maturation of reproductive buds for the next year's harvest throughout the reproductive cycle. The planting of cultivars with a late or very late cycle is not recommended in regions with milder air temperatures, for harvest may coincide with the beginning of flowering for the next harvest, which can damage flowers (or buds), as well as risk frost on green fruit. Although frost rarely occurs in Central Brazil, the use of mechanized harvesting, widely diffused in this region, may result in yield loss for the next harvest, due to damage caused to flowers or floral buds in late maturity cultivars, especially when water stress technology is not adopted to promote uniform flowering. Thus, study and differentiation of the maturation cycle of the genotypes under assessment is of paramount importance. Furthermore, according to the same author, the highest yielding cultivars are those of medium or late cycle. Therefore, identification of high yielding materials with early cycles would be of great value, especially to reduce the risk of rainfall during harvest.

Repeatability is a genetic parameter that expresses the proportion of the total variance that is explained by the variations proportioned by the genotypes and by the permanent alterations attributed to the common environment that act on the genotypes. Through study of repeatability, the number of measurements needed to predict the real value of a genotype can be estimated. Repeatability provides the maximum value that heritability in the broad sense can achieve, expressing the proportion of the phenotypic variance that is attributed to genetic differences along with confused with the permanent effects acting on the genotype (Cruz et al. 2012). Thus, through repeatability, one can compare distinct individuals by means of data collected over time, which is quite useful when considering a highly heterozygous heterogamous species like coffee, without the need to reproduce clones of a population of many distinct genotypes. This allows evaluation of a large number of materials in a reduced space (Della Bruna et al. 2012). Besides, since it is related to the minimum number of measurements necessary for accurate selection of superior genotypes, repeatability and maximum broad-sense heritability allows quantifying the maintenance of clone superiority overtime (Rocha et al. 2015).

Perennial plant species, such as coffee, have peculiar biological aspects, for instance, a long reproductive cycle, accentuated annual oscillation of production (resulting in a biennial cycle), overlapping of generations, trait expression over several years, and differences in days to maturity and yield longevity. These characteristics lead to some consequences, such as use of the selected genotypes for several years, use of evaluations repeated in each individual over time, and reduction in the survival rate of individual plants over the time of experiment. This reduction tends to generate unbalanced data for use in estimation of genetic parameters and in prediction of additive and genotypic values. Due to these agronomic peculiarities, coffee breeding is difficult, and the use of special methods to estimate genetic parameters and to predict genetic values is recommended (Oliveira et al. 2011). Thus, the standard analytical procedure that has been recommended for studies in quantitative genetics and also for selection in perennial plants is the mixed model methodology. This approach allows accurate and unbiased prediction of the genetic values even under imbalance, and it also facilitates simultaneous use of information on the individual and the family and of measures repeated over time, providing more accurate estimates of the components of genetic variation and of individual genetic values (Pereira et al. 2013).

The objective of this study was to use repeatability to evaluate the yield and the maturation cycle of $C$. canephora genotypes irrigated in the Cerrado and determine the genetic and phenotypic parameters of the population and the different maturation cycles of these genotypes in order to select high-yielding genotypes for the region.

\section{MATERIAL AND METHODS}

The study was performed in the experimental field of Embrapa Cerrados in Planaltina (lat 15 35' 30,00" S, long 470 42' 30,00" W, and alt of $1007 \mathrm{~m}$ asl), Distrito Federal, Brazil, on a soil classified as a clayey Latossolo Vermelho distrófico típico (Oxisol). 
In previous years, the area had been planted to annual crops. The trial was established in April 2009, with a spacing of $3.5 \mathrm{~m}$ between rows and $1.0 \mathrm{~m}$ between plants. The $85 \mathrm{C}$. canephora genotypes studied were obtained from natural breeding in an isolated experimental field of the cultivar Robusta Tropical (EMCAPER 8151) from the Capixaba Research and Rural Extension Company (Empresa Capixaba de Pesquisa e Extensão Rural) - EMCAPER. A center pivot sprinkler irrigation method was adopted. The irrigation management criterion was based on monitoring the climate, and the periodicity of irrigation was every five days, according to the Cerrado Irrigation Monitoring Program (Rocha et al. 2008). To synchronize flowering, irrigation was suspended on July 1 and resumed when at least $80 \%$ of the flower buds reached the E4 stage, with a final date for return to irrigation on September 4 of each year. In the years in which the experiment was performed, the return to irrigation always occurred on the final date. The practice of subjecting plants to water deficit breaks flower bud dormancy and thus concentrates flowering and fruit maturation in each plant.

In the experimental field, there were about 3,500 genotypes planted without replication repetition. From the harvest data of the 2011/12, 2012/13, and 2013/14 crop years, 85 materials were selected with minimum production of seven liters per plant in each of the three years and production variation lower than $25 \%$. According to Silva et al. (2018), lower biannual variation is as important as yield potential for the selection of clones with higher yield stability that maintain their superiority overtime.

These materials were used in statistical analysis, through repeatability, to obtain the genetic parameter values, phenotypic values, and determination of yield. Preliminary observations, especially those performed by Carneiro et al. (2013), allowed this pre-selection and non-selection of late maturation materials, because of the risk of a later harvest operation compromising production in the following year by causing damage to flowers and flower buds. The standard deviation and the coefficient of variation of the yield of each material during the three harvests were calculated.

The maturation cycles were determined through weekly observation of the genotypes, following the scale developed by Pezzopane et al. (2003), in which a change in level was considered only when at least $80 \%$ of the fruit was at the same maturation stage. That way, considering the cherry stage as ideal for harvest, the time between the resumption of irrigation and the cherry stage, in days, was counted, ensuring that each material reached the cherry stage. The difference in days to reach the cherry stage between the earliest material ( 243 days) and the latest (293 days) was 50 days. Thus, three intervals were made in the mean values $(13,25$, and 38 days, approximately), forming four maturation groups, which were denominated very early (243-255 days), early (256-267), medium (268-280), and semi-late (281-293).

Statistical analysis was performed through the Statistical System and Computerized Genetic Selection via Mixed Linear Models, Selegen - REML/BLUP (Resende 2016), using the Basic Model of Repeatability Without Design (model 63 of the program). The Mixed Model Methodology was used to obtain the Best Linear Unbiased Prediction (BLUP) of the genotypic effects and the Restricted Maximum Likelihood (REML) process for estimation of the components of variance and the genotypic parameters.

The basic model of repeatability without design is used when repeated data are taken from individual plants with no defined experimental design. The statistical model is $y=X m+W p+e$ where $y$ is the data vector, $m$ is the vector of the effects of measurement (assumed as fixed) added to the overall average, $p$ is the vector of the permanent effects of plants (genotypic effects plus environment effects considered to be permanent, assumed to be random), and $e$ is the error or residue vector (random). Capital letters represent the incidence matrices for the referred effects.

The following values were then obtained: coefficient of repeatability, which, in this case, is considered equal to heritability; permanent phenotypic variance among plants (genotypic variance plus permanent environmental variance from one crop season to the next); temporary environmental variance (environmental variance of each crop season); individual phenotypic variance; average repeatability of $m$ crops or repeated measures; accuracy of selection based on the average of $m$ harvests or repeated measurements; and the gain from selection for yield in liters per plant.

\section{RESULTS AND DISCUSSION}

Table 1 shows the yield of the genotypes in each of the years evaluated, their averages, coefficients of variation of yield, cycle in days from return to irrigation to the cherry stage, and cycle classification. 
The highest yields in each of the harvests were obtained by genotypes $82(20 \mathrm{~L}), 40$ (20 L), and $74(19 \mathrm{~L})$ in the 2012, 2013, and 2014 harvests, respectively. The overall average yield was $10.79 \mathrm{~L}$ per harvest, and the average number of days to reach the cherry stage was 268.6 . The average standard deviation of yield was $1.82 \%$, while the coefficient of variation of the yield values over the three years was $16.83 \%$.

Table 1. Yield, in liters per plant, for three consecutive harvests, cycle (Days) from resumption of irrigation to the cherry stage, cycle classification (C), yield averages, and coefficients of variation of 85 genotypes (Gen) of $C$. canephora under irrigation in the Cerrado

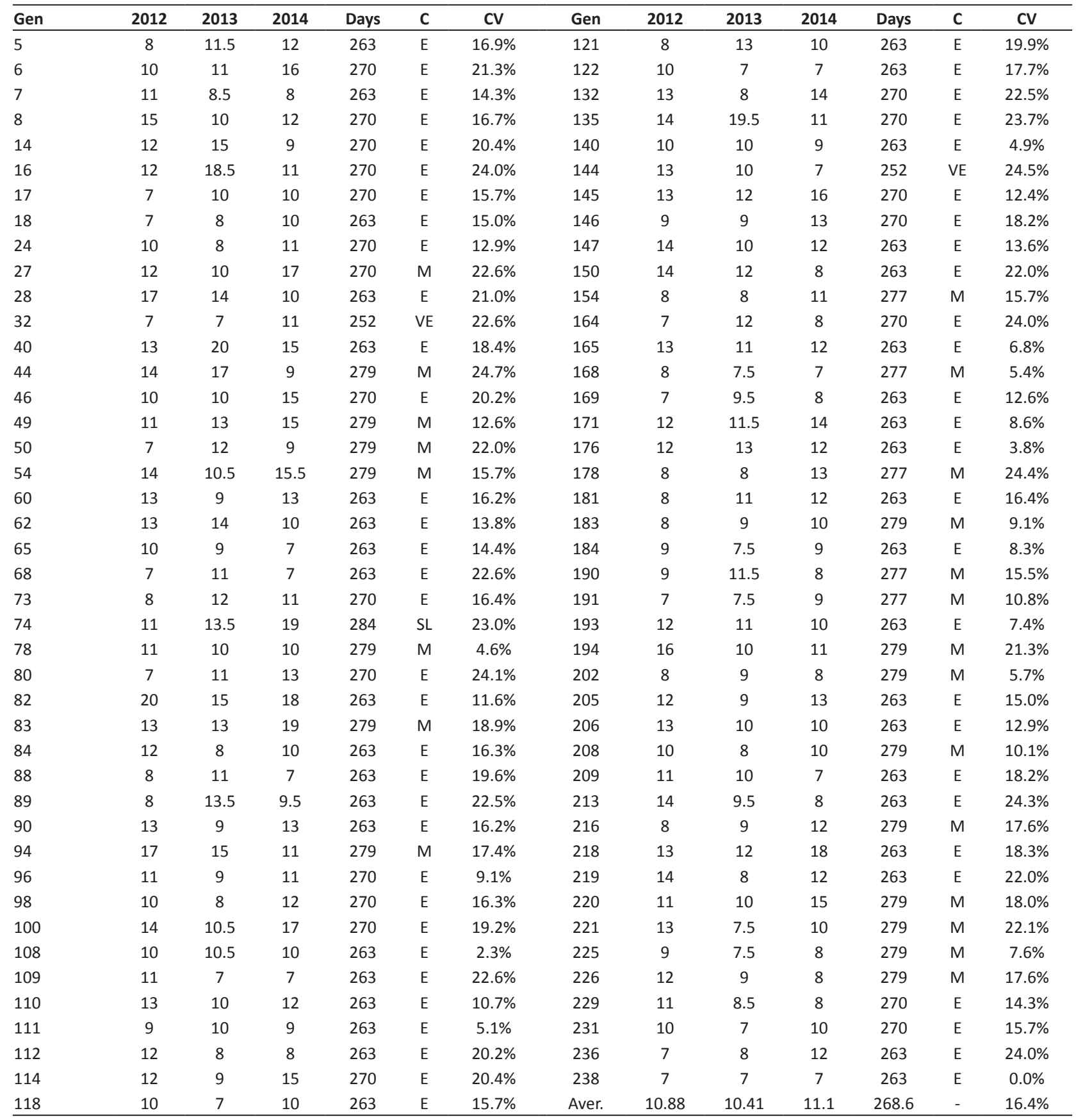

Classes of cycle classification: $\mathrm{VE}=$ very early; $\mathrm{E}=$ early; $\mathrm{M}=$ medium; $\mathrm{SL}=$ semi late. 
The genotypes with the highest yield averages over the three harvests were 82 , with an average of $17.67 \mathrm{~L}$ per harvest, and 40, with an average of $16.0 \mathrm{~L}$. The main difference between the two was that genotype 82 had a more stable yield, with variation of less than $12 \%$ over the 3 years. This factor, considering the desirability of materials with low bianniality, can be of great value. Furthermore, genotype 82 was classified as early, with a cycle of 263 days from return to irrigation to the cherry stage, whereas genotype 40 took 279 days. From the aspect of yield stability, some genotypes stood out through very low variation (less than $10 \%$ ), or even had no variation. The results obtained from repeatability analysis in each of the situations tested are shown in Table 2.

The permanent phenotypic variance among plants, the variance regardless of temporary environmental effects, i.e., the effects of the environment in each crop season, represented $30 \%$ of the total phenotypic variation. This factor shows the lower effect of temporary variations on the response of the materials, or greater adaptation to local conditions.

Individual repeatability, which in this case can be considered equivalent to heritability, reached a value over 0.38 (Table 2). According to Resende (2009), repeatability values between 0.30 and 0.60 are considered medium. However, considering the low number of repetitions (only 3 ) and that coffee is a perennial species, these values of repeatability will certainly be more consistent with a higher number of repetitions, or as the cycles of selection and evaluation of genotypes progress.

In addition, when considering the average repeatability $(\mathrm{rm})$, the value rises to $55.5 \%$, a value, according to the same author, very close to the values considered high for this parameter. Ramalho et al. (2016), working with robusta coffee in the state of Rondônia, obtained coefficients of repeatability of 0.43 in an analysis of four harvests, while they obtained 0.427 for heritability in the broad sense. The proximity of these two values is noteworthy, which corroborates the idea that the two parameters may be considered equivalent. Another factor to be considered is that yield is highly influenced by environment.

Repeatability can be interpreted as the maximum value of heritability in the broad sense, since it expresses genotypic variance added to the permanent effects of environment. In this sense, the repeatability values obtained in this study are close to those perceived by Ramalho et al. (2016) working with robusta coffee in the state of Rondônia. In addition, Mistro et al. (2008) observed values for the repeatability coefficient between 0.26 and 0.63 , similar to those presented here. It should be noted, however, that these authors used six and nine repetitions, respectively, always with two plants per plot, whereas here, only one repetition was used, with one plant per plot, and harvests for three consecutive years.

The values of accuracy in relation to the number of measurements are shown in Table 3. Fonseca et al. (2004) cited that four successive harvests would be sufficient for selection of robusta coffee genotypes for yield with an accuracy of $80 \%$, a value also considered quite satisfactory by Resende (2009), for whom selective accuracy between 0.7 and 0.9 is considered high. Pereira et al. (2013) obtained estimated accuracy of 0.84 in three harvests in an experiment with four repetitions in two years. In the experiment described here, the accuracy obtained in three harvests was approximately $75 \%$, and estimated at $79 \%$ with four harvests, very close to the values obtained by the authors cited. Selective accuracy depends on the heritability and repeatability of the trait, the quantity and quality of information, and the procedures used to predict
Table 2. Values of the genetic parameter obtained from analysis of repeatability of $\mathrm{C}$. Canephora in three harvests

\begin{tabular}{lc}
\hline Genetic Parameter & Value \\
\hline Vpp & 2.5479 \\
Vte & 5.9377 \\
Vip & 8.4049 \\
$r$ & $0.2935 \pm 0.0938$ \\
rm & 0.5549 \\
Acm & 0.7449 \\
\hline Overall Average & 10.79
\end{tabular}

Vpp: Permanent phenotypic variance among plants; Vte: variance of temporary environment; Vip: individual phenotypic variance; $r=h^{2}$ : individual repeatability; $\mathrm{rm}$ : average repeatability; $\mathrm{Acm}$ : average accuracy of the selection based on the average of $m$ harvests.

Table 3. Selection accuracy in accordance with the number of repeated measurements for yield in robusta coffee

\begin{tabular}{lc}
\hline Nr. of measurements or repetitions & Accuracy \\
\hline 1 & 0.5418 \\
2 & 0.6737 \\
3 & 0.7449 \\
4 & 0.7902 \\
5 & 0.8216 \\
6 & 0.8448 \\
7 & 0.8626 \\
8 & 0.8768 \\
9 & 0.8883 \\
10 & 0.8978 \\
\hline
\end{tabular}


genetic values. Selective accuracy is a measure associated with accuracy in selection, that is, it refers to the correlation between predicted genetic values and true genetic values of individuals, and the greater the accuracy in an individual assessment, the greater the confidence in the assessment and in the predicted genetic value of the individual. Accuracy is also the main element of genetic progress that the breeder can change in order to maximize genetic gain, and refers to the correlation between the true genotypic value of the genetic material and the estimated or predicted value (Lopes et al. 2018).

Table 4. Classification, genotype (Gen), phenotypic value ( $f p)$, sum between phenotypic and average value $(u+f p)$, selection gain (in liters per plant), and new average of the population of 85 genotypes of $C$. canephora under irrigated growing in the Cerrado

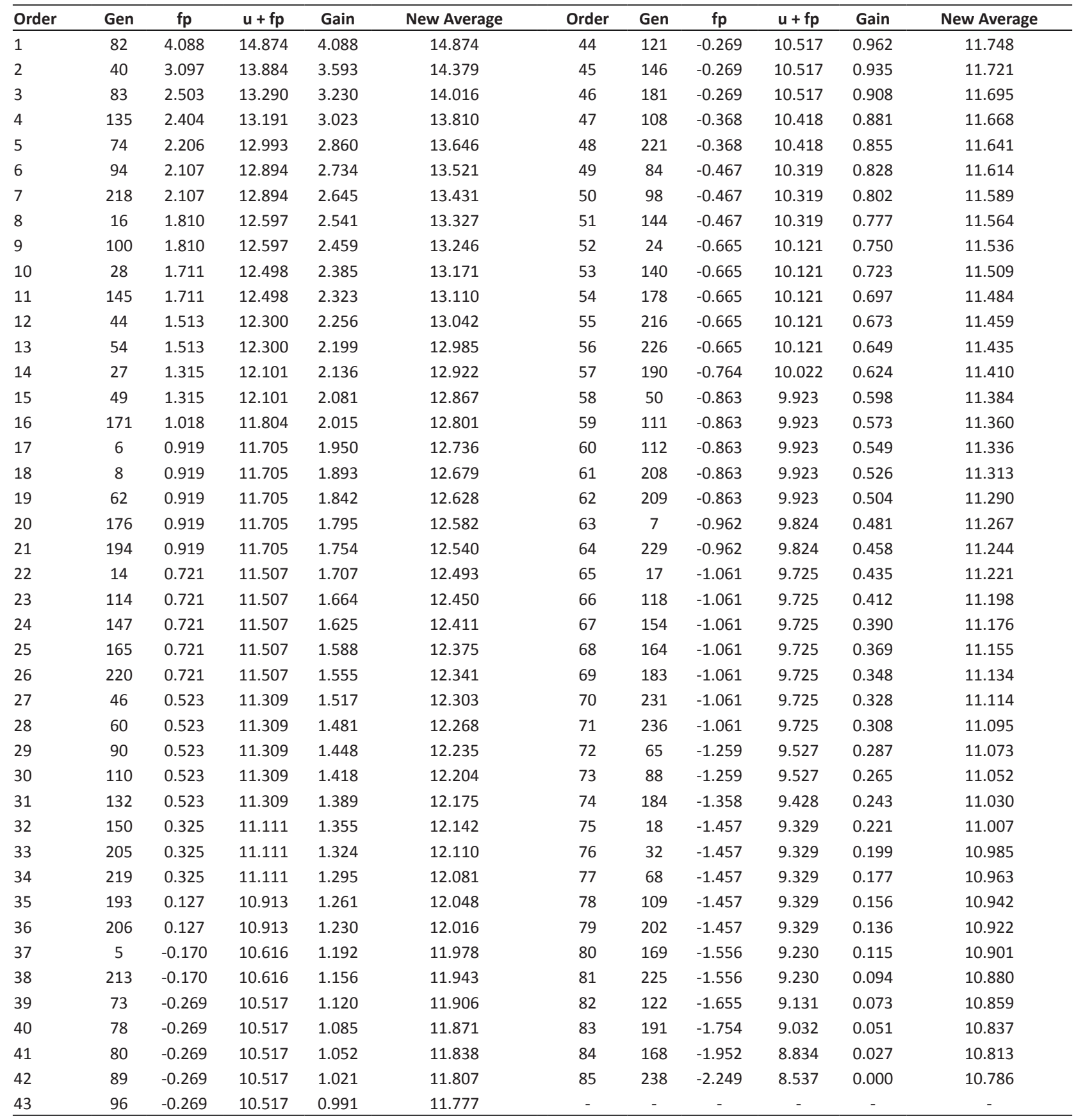


Working with the repeatability coefficient in peach, Della Bruna et al. (2012) obtained a variation of the coefficient of repeatability between 0.22 and 0.29 for the fruit yield per plant trait, with estimates of accuracy (Acm) between 60.0 and $75.0 \%$. The repeatability $(0.30)$ and the accuracy $(75 \%)$ obtained in this experiment are therefore within the values observed for other fruit plants. Pedro Junior et al. (2013), working with lemon tree cultivation, obtained coefficients of individual repeatability $(r)$ around 0.1 , reaching 0.35 in the average of 5 harvests. The accuracy obtained by these authors was $58 \%$ in one harvest and $84 \%$ in five harvests, values near those shown here, $54.2 \%$ and $82.1 \%$ in one and five harvests, respectively. It is noted, therefore, that an increase in the number of measurements allows an increase in the accuracy of selection. However, these increases become smaller and less significant each year, and it can be inferred that from the fifth harvest on, increases in accuracy would not justify the necessary input of resources.

The variability of the population allows expressive gains from selection of superior genotypes, up to approximately $40 \%$ of the mean of the population under study. Ramalho et al. (2016) obtained estimates of selection gains of $43.8 \%$ in the first year, working with robusta coffee in the state of Rondônia. Therefore, the results presented here are also close to those found by those authors.

The prediction of permanent phenotypic value is extremely relevant for it allows selection of individuals that will be cultivated in an environment similar to the one under evaluation, and thereby the additive, dominance, and permanent effects of environment are capitalized. In addition, it is possible to select genotypes for vegetative propagation outside the environment in which they were evaluated, and thus the additive and dominance effects are capitalized (Della Bruna et al. 2012). The phenotypic values of the individuals, as well as the selection gain inherent to each of them, are shown in Table 4.

Thus, there is genetic variability within the population studied in relation to yield and maturation cycle. Promising genotypes were found for production under irrigation within the population of Coffea canephora studied in the Cerrado region of Brazil. Materials have been identified for utilization in crosses to maximize heterotrophic effects and gene complementarity within a breeding program for robusta coffee under irrigation management.

\section{REFERENCES}

Carneiro FA, Rêgo ECS, Costa TS, Oliveira SA, Duarte KE, Rocha OC, Rodrigues GC, Carvalho MAF, Marraccini P, Grattapaglia D, Bartholo GF, Guerra AF and Andrade AC (2013) Avaliação fenotípica de uma população de Coffea canephora var. Conilon cultivada em altitude elevada, visando um programa de seleção genômica (SGA) em cafeeiro. In Resumos expandidos do 8 simpósio de pesquisa dos cafés do Brasil. Embrapa Café, Brasília, p. 307.

Cruz CD, Regazzi AJ and Carneiro PC (2012) Modelos biométricos aplicados ao melhoramento genético. $4^{\text {th }}$ edn, UFV, Viçosa, $514 p$.

Della Bruna E, Moreto LM and Dalbó MA (2012) Uso do coeficiente de repetibilidade na seleção de clones de pessegueiro para o litoral sul de Santa Catarina. Revista Brasileira de Fruticultura 34: 206-215.

Fernandes ALT, Partelli FL, Bonomo R and Golynski A (2012) A moderna cafeicultura dos cerrados brasileiros. Pesquisa Agropecuária Tropical 42: $231-240$.

Fonseca AFA, Sediyama T, Cruz CD, Sakaiyama NS, Ferrão MAG, Ferrão RG and Bragança SM (2006) Divergência genética em café conilon. Pesquisa Agropecuária Brasileira 41: 599-605.

Fonseca AFA, Sediyama T, Cruz CD, Sakaiyama NS, Ferrão RG, Ferrão MAG and Bragança SM (2004) Repeatability and number of harvests required for selection in robusta coffee. Crop Breeding and Applied Biotechnology 4: 325-329.
Lopes RR, Franke LB, Souza CHL, Graminho LA and Pereira EA (2018) Genetic parameters and predicted gains with selection of interespecific hybrids of Paspalum for seed production. Crop Breeding and Applied Biotecnology 18: 284-291.

Mistro JC, Fazuoli LC, Guerreiro Filho O, Silvarolla MB and Thoma-Braghini M (2008) Determination of the number of years in Arabic coffee progenies selection through repeatability. Crop Breeding and Applied Biotechnology 8: 79-84.

Oliveira ACB, Pereira AA, Silva FL, Rezende JC, Botelho CE and Carvalho GR (2011) Prediction of genetic gains from selection in Arabica coffee progenies. Crop Breeding and Applied Biotechnology 11: 106-113.

Partelli FL, Batista-Santos P, Scorri-Campos P, Pais IP, Quartina VL, Vieira HD and Ramalho JC (2011) Characterization of the main lipid components of chloroplast membranes and cold induced changes in Coffea spp. Environmental and Experimental Botany 74: 194-204.

Pedro Junior J, Blumer S and Resende MDV (2013) Avaliação genética de seleções e híbridos de limões cravo, volkameriano e rugoso como porta-enxertos para laranjeiras valência na presença da morte súbita dos citros. Revista Brasileira de Fruticultura 35: 199-209.

Pereira TB, Carvalho JPF, Botelho CE, Resende MDV, Rezende JC and Mendes ANG (2013) Eficiência da seleção de progênies de café $F_{4}$ pela metodologia de modelos mistos (REML/BLUP). Bragantia 72: 230-236.

Pezzopane JRM, Júnior MJP, Thomaziello RA and Camargo MBP (2003) 


\section{MR Santin et al.}

Escala para avaliação de estádios fenológicos do cafeeiro arábica. Bragantia 62: 499-505.

Ramalho AR, Rocha RB, Souza FF, Veneziano W and Teixeira AL (2016) Progresso genético da produtividade de café beneficiado com a seleção de clones de cafeeiro 'Conilon'. Ciência Agronômica 47: 516-523.

Resende MDV (2009) Genética biométrica e estatística no melhoramento de plantas perenes. Embrapa Informação Tecnológica, Brasília, 975p.

Resende MDV (2016) Software Selegen-REML/BLUP: a useful tool for plant breeding. Crop Breeding and Applied Biotechnology 16: 330-339.

Rocha RR, Ramalho AR, Teixeira AL, Souza FF and Cruz CD (2015) Adaptabilidade e estabilidade da produção de café beneficiado em
Coffea canephora. Ciência Rural 45: 1531-1537.

Rocha OC, Guerra AF, Silva FAM, Machado Júnior JRR, Araújo MC and Silva HC (2006) Programa para monitoramento de irrigação do cafeeiro no Cerrado. In VIII Simpósio brasileiro de pesquisa em cafeicultura irrigada. Universidade Federal de Viçosa, Viçosa, p. 61-64.

Rodrigues WP, Vieira HD, Campostrini E, Figueiredo FAMMA, Ferraz TM, Partelli FL and Ramalho JC (2016) Physiological aspects, grouwth and yield of 'Coffea' spp. in areas of high altitude. Australian Journal of Crop Science 10: 666-674.

Silva DO, Ferreira FM, Rocha RB, Espindula MC and Spinelli VM (2018) Genetic progress with selection of Coffea canephora clones of superior processed coffee yield. Ciência Rural 48: e20170443. 